\title{
Fas-Ligand and Immune Privilege: The Eyes Have It
}

\author{
Dear Editor,
}

Some tissues in the body seem to exclude or dampen immune responses, a phenomenon called immune privilege. For several years, there has been a general consensus this process is mediated, at least in part, by the expression of Fasligand (FasL, CD95-L, Apo-1L), which induces apoptosis in infiltrating immune cells. However, this idea has recently lost favor, in part through observations with tumors but also by a misunderstanding (or misrepresentation) of the literature. For example, a recent letter ${ }^{1}$ concluded 'that the body of evidence supporting a role for Fas in immune privilege is lacking'. This statement summarily dismissed a role for FasL in privilege as it pertains to all organ and tumors systems, a point also made in a recent review article. ${ }^{2}$ We would like to identify for the readers of CDD a large body of literature to the contrary, particularly as it relates to FasL and immune privilege in the eye.

The initial studies on FasL and Immune privilege in the eye showed that FasL helped control lymphocyte proliferation and tissue damage in response to viral infection. ${ }^{3}$ In addition, FasL helped protect corneal transplants from rejection ${ }^{4}$ and killed lymphocytes leading to immune tolerance. ${ }^{5}$ Since these initial findings, there are now over 20 papers confirming these studies (easily made available). These included confirmation of the initial studies ${ }^{6,7}$ and confirmation with other pathogens. ${ }^{8}$ Even in the absence of ideal antibodies, there has been high quality data on functional FasL in the eye using $\mathrm{Fas}^{+}$target lines. In rodents, corneal grafts without FasL are rejected at nearly $100 \%$ and FasL protects corneal tissue even following heterotopic transplantation..$^{9,10}$ In humans, functional FasL expression was found to correlate with spontaneous remission in patients with acute anterior uveitis. ${ }^{11}$ Studies have been extended to show that FasL functions to control angiogenesis in the eye. ${ }^{12}$ Thus, the statement that 'evidence...is lacking' is without foundation.

It was also stated that 'reports of FasL-mediated immune privilege in the eye do not have clinical corroboration'. ${ }^{1}$ This was concluded from an anecdotal observation of ALPS patients, who are genetically defective in Fas signaling, ${ }^{13}$ but apparently do not have 'eye problems'. Inherent in this unsubstantiated statement are the assumptions that: (a) the internal structures of the eye are constantly bombarded with inflammatory cells and pathogens; and (b) the immune response in these patients is actually capable of causing damage. We know the first is not the case due to the blood/ ocular barrier and numerous innate defense mechanisms present in the eye making it remarkably resistant to infection. Our point here is further emphasized by observations in gld and $I p r$ mice,,$^{3,8}$ animals that lack functional FasL and Fas, respectively. These mice rarely have spontaneous inflammation (or infection) in the eye.
The role of FasL is revealed only when cell proliferation in response to infection of young mice can not be controlled. As to our second point, it is not clear that the immune response in ALPS patients is intact. It was reported that their T-cells are unresponsive, they have elevated plasma concentrations of the inhibitory cytokine IL-10, and they are biased towards a Th2-type response. ${ }^{13}$ Th2-type responses are inhibitory to ocular inflammatory diseases. ${ }^{14} \mathrm{~A}$ more reasonable conclusion would be that the eye does a good job in controlling inflammation under normal conditions, however, challenge with a pathogen and subsequent invasion by competent inflammatory cells requires FasL to help control proliferation.

Results from the autoimmune model in the eye ${ }^{15}$ are also used to dispute the role of FasL in immune privilege. These studies are reminiscent of the EAE system, where similar experiments led to the conclusion that Fas/FasL played no role in protecting the brain, but were involved in pathogenesis. ${ }^{16}$ Further experiments, ${ }^{17,18}$ however, showed that the situation was much more complicated, especially when it was discovered that FasL induced in the CNS was required for spontaneous remissions during the course of induced disease.

Another incorrect position inherent in these arguments is that if FasL does not act alone in immune privilege, then it plays no role. ${ }^{1,2}$ This assumption is inconsistent with the current literature on immune privilege, since it has been demonstrated by numerous studies ${ }^{19}$ that there are at least eight participants in the phenomenon in the eye (FasL is only one). For example, even the proinflammatory properties of FasL overexpression can be controlled by adding an additional mediator (namely $\operatorname{TGF} \beta$ ), ${ }^{20}$ and this has been shown to participate in immune privilege. ${ }^{19}$

Perhaps the major reason that FasL and immune privilege is criticized stems from studies showing that in some cases enforced, ectopic expression leads to inflammation. ${ }^{1,2}$ However, if one takes into account all the available evidence, one is forced to conclude that the body of evidence supporting FasL-dependent inflammatory responses under physiological conditions (i.e. not involving forced expression) is lacking. Physiological evidence suggests that expression of FasL in the eye, ${ }^{3}$ the liver and intestine, ${ }^{21}$ and on T-cells, ${ }^{22}$ is anti-inflammatory. It should also be noted that forced expression of FasL does confer protection (immune privilege?) on tissue and cells. Although these studies were not cited in critiques of the field, ${ }^{1,2}$ FasL gene transfer ameliorated collagen-induced arthritis, ${ }^{23}$ prevented activation of T-cells by FasL expressing APC's, ${ }^{24}$ and prevented thyroid disease. ${ }^{25,26}$

One last issue that is often raised in challenge to the idea that FasL functions in immune privilege are the well known difficulties in the use of some antibodies to detect 
FasL, especially in mice (but also human). While the specificity and utility of these anti-FasL antibodies continues to be discussed, ${ }^{27-29}$ the demonstration that FasL is expressed in the eye (and other privileged tissues, mentioned above) is based on the use of functional assays (induction of apoptosis in $\mathrm{Fas}^{+}$but not Fas ${ }^{-}$target cells) and effects in mutant mice ( $g / d$ and $/ p r)$. Therefore, we can exercise care in the interpretation of immunohistochemistry in some cases without compromising the conclusions of the papers we have cited.

We hope that open exposure of the literature concerning FasL and immune privilege in the eye will permit readers of CDD to have a less myopic view than recently discussed. However, science is a process and the resolution of this controversy will be informative. Mark Twain said, 'Theories don't prove nothing, they only give you a place to rest on, a spell, when you are tuckered out butting around and around trying to find out something there ain't no way to find out'. However, he also said, 'There is no use arguing against a settled conviction'. In the case of FasL and immune privilege in the eye, we hope he was wrong about that.

\section{TA Ferguson ${ }^{1}$ and DR Green ${ }^{* 1}$}

${ }^{1}$ Washington University School of Medicine, St. Louis, MO, USA;

2 LaJolla Institute for Allergy and Immunology, San Diego, CA, USA

${ }^{*}$ Corresponding author: LaJolla Institute for Allergy and Immunology,

San Diego, CA, USA. E-mail: dgreen5240@aol.com
1. Restifo N (2001) Nature Med. 7: 259

2. Restifo N (2001) Nature Med. 7: 271-274

3. Griffith TS et al. (1995) Science 270: 1189-1192

4. Stuart PM et al. (1997) J. Clin. Invest. 99: 396-402

5. Griffith TS et al. (1996) Immunity 5: 7

6. Kawashima H et al. (1997) Eur. J. Immunol. 27: 2490-2494

7. Yamagami S et al. (1997) Transplantation 68: 1107-1111

8. Hu MS et al. (1999) Infection and Immunity 67: 928-935

9. Hori J et al. (2000) Invest. Ophthalmol.Vis. Sci. 41: 443-452

10. Hori J, Joyce NC and Streilen JW (2000) Invest. Ophthalmol. Vis. Sci. 41:30323042

11. Dick A et al. (1999) Invest. Ophthalmol. Vis. Sci. 40: 2258-2267

12. Kaplan HJ et al. (1999) Nature Med. 5: 292-297

13. Straus et al. (1999) Ann Intern Med. 130: 591-601

14. Yamada J et al. (1999) J. Immunol. 162: 5247-5455

15. Wahlsten et al. (2000) J. Immunol. 165: 5480-5486

16. Waldner et al. (1997) J. Immunol. 159: 3100-3103

17. Suvannavejh GC et al. (2000) J. Clin. Invest. 105: 223-231

18. Sableko-Downes KA et al. (1999) J. Exp. Med. 189: 1195-1205

19. Ferguson TA and Griffith TS (1997) Immunol. Rev. 156: 167-184

20. Chen JJ et al. (1998) Science 282: 1714-1717

21. Bonfoco E et al. (1998) Immunity 9: 711-720

22. Van Parijs L and Abbas AK (1996) Curr. Opin. Immunol. 8: 355-361

23. Zhang H et al. (1997) J. Clin. Invest. 100: 1951-1957

24. Zhang $\mathrm{H}$ et al. (1999) J. immunol. 162: 1423-1430

25. Batteaux F et al. (1999) J. Immunol. 162: 603-608

26. Batteaux F et al. (2000) J. Immunol. 164: 1681-1688

27. Baker JR and Bretz JD (2000) Cell Death Differ. 7: 8-9

28. Fiedler $P$ and Eibel $H(2000)$ Cell Death Differ. 7: 126-128

29. Herr l et al. (2000) Cell Death Differ. 7: 129-130 